\title{
LA LEGISLACIÓN LABORAL ESPAÑOLA BAJO EL PUNTO DE MIRA DEL TRIBUNAL DE JUSTICIA DE LA UNIÓN EUROPEA
}

\author{
SPANISH LABOR LEGISLATION UNDER THE POINT \\ OF VIEW OF THE COURT OF JUSTICE OF THE EUROPEAN UNION
}

\author{
ANA ABA CATOIRA \\ Universidade da Coruña
}

Recibido: 11/09/2018

Aceptado: 16/10/2018

Resumen: Las sentencias dictadas por el Tribunal de Justicia de la Unión Europea marcan el camino a seguir por los órganos nacionales en materia laboral sobre muchas cuestiones en las que se aprecia la contravención del Derecho Europeo por las normas internas. España está en el punto de mira respecto a varias cuestiones que ponen el acento sobre el régimen de contratación laboral y el elevado número de contratos que se firman de esta naturaleza, sobre todo en el ámbito de las Administraciones Públicas. El grueso de este estudio se ocupa de la jurisprudencia sentada a partir de septiembre de 2016 sobre derechos indemnizatorios que ha sido modificada en nuevas sentencias dictadas en enero de 2018. No olvidamos referenciar algunas otras cuestiones sobre las que se ocupan otras sentencias europeas también muy recientes. La institución europea estudia la adecuación de las legislaciones nacionales respecto a la legislación supranacional europea y ello puede conllevar modificaciones legislativas para afrontar la necesaria adecuación a la que obliga el principio de primacía.

Palabras Clave: contratación laboral, indemnización, Tribunal de Justicia de la Unión Europea.

Abstract: The judgments issued by the Court of Justice of the European Union mark the way forward for the national labor bodies on many issues in which it appreciates the contravention of European law by internal rules. Spain is in the spotlight on several issues that put the accent on the employment contract regime and the high number of contracts that are signed of this nature, especially in the field of Public Administrations. The bulk of this study deals with the jurisprudence established as of September 2016 on compensation rights that has been modified in new judgments issued in January 2018. We do not forget to mention some other issues that are dealt with by other European judgments that are also very recent. The European institution is studying the adequacy of national legislation with regard to European supranational legislation and this may lead to legislative changes to face the necessary adaptation to which the principle of primacy requires.

Key Works: labor hiring, compensation, Court of Justice of the European Union.

SUMARIO: INTRODUCCIÓN. 1. PRESENTACIÓN DE LAS CUESTIONES A DEBATE: LA PÉRDIDA DEL CARÁCTER TUITIVO DEL DERECHO LABORAL. 2. SUPUESTOS ANALIZADOS POR EL TRIBUNAL DE JUSTICIA DE LA UNIÓN EUROPEA. 2.1. Indemnizaciones laborales ante la extinción de la relación laboral. 2.2. Encadenamiento de contratos 
temporales. 3. DETERMINACIÓN DE LA BASE DE CÁLCULO DE LA PRESTACIÓN. 4. LA EXTINCIÓN DEL CONTRATO POR FALTAS DE ASISTENCIA: PERSONAS CON DISCAPACIDAD. 5. EL T.J.U.E RECTIFICA Y CONFIRMA LA ADECUACIÓN DE LA LEGISLACIÓN NACIONAL AL DERECHO COMUNITARIO. 6. BIBLIOGRAFÍA.

\section{INTRODUCCIÓN}

En los últimos tiempos el Tribunal de Justicia de la Unión Europea ha dictado varias sentenciasque ponen en entredicho la adecuación de la legislación laboral española al Derecho europeo. No son pocas las resoluciones comunitarias, "pero" obligados a realizar una selección, hemos aplicado el criterio de la novedad o del "impacto" dado el cambio que han supuesto en las posturas ya consolidadas en nuestro país. En 2016 varias resoluciones de este órgano judicial incidieron directamente sobre el sistema de contratación temporal vigente ${ }^{1}$, concretamente analizando si la norma nacional de aplicación es conforme al Acuerdo Marco comunitario, en lo que concierne al sistema indemnizatorio que establece diferencias entre las personas contratadas con carácter temporal y aquéllas con un contrato de trabajo fijo. En virtud de la doctrina contenida en estas sentencias, en todos los supuestos de rescisión contractual existe el derecho a percibir la misma compensación económica, salvo que existan "razones objetivas" que justifiquen la diferencia, declarando que la duración determinada o indeterminada del contrato no puede tener esta consideración. Sucede que la doctrina sentada en la sentencia dictada en el caso De Diego Porras vs. Ministerio de Defensa fue objeto de varias solicitudes de aclaración presentadas por el Tribunal Supremo y otros órganos judiciales, un hecho que ya hizo pensar, hace unos meses, que, de producirse un cambio sustancial de criterio, se superaría el terremoto de 2016 que generó una enorme conflictividad a nivel interno ${ }^{2}$.Así ha sido, con las dos sentencias dictadas el pasado

1 Sentencia del Tribunal de Justicia de la Unión Europea, Sala Décima, de 14 de septiembre de 2016, asunto C-596/14, Caso Ana De Diego Porras y Ministerio de Defensa, sobre la protección de los trabajadores laborales temporales en caso de extinción contractual válida siendo una Administración Pública la empleadora; Sentencia, de 14 de septiembre de 2016, asunto C-16/15, Caso Sra. Pérez López y Servicio Madrileño de Salud, respecto a los sucesivos nombramientos del personal estatutario temporal en el ámbito sanitario público; Sentencia, de 14 de septiembre de 2016, asuntos C-184/15 y C-197/15 acumulados, Sra. Martínez Andrés y Servicio Vasco de Salud y Sr. Castejana López y Ayuntamiento Vitoria-Gasteiz, referida a la protección jurídica frente a la utilización abusiva de los contratos o relaciones de servicio de duración determinada en el ámbito de las administraciones públicas. Auto del Tribunal Superior de Justica de 2 de septiembre de 2016, asunto C-631/15, Caso Carlos Álvarez Santirso y Consejería de Educación del Principado de Asturias, relativo a un profesor (funcionario interino docente no universitario) con sucesivos contratos de duración determinada en el sector público, cuestionando un complemento salarial que no se abona al funcionariado interino vinculado al Plan de evaluación de la carrera docente y Auto de 21 de septiembre de 2016, C-614/15, asunto Rodica Popescu y Directia Sanitar Veterinarasipentru Siguranta Alimentekir Gorj, sobre la contratación de una auxiliar veterinaria en el ámbito de la inspección veterinaria de Rumania con sucesivos contratos de duración determinada en el sector público.

2 El alto número de controversias interpretativas ha puesto de manifiesto las contradicciones existentes tanto en la jurisdicción social como en la contencioso-administrativa. La inseguridad jurí- 
mes de junio en las que el Tribunal europeo rectificó su criterio de 2016, devolviendo su libertad legislativa a los estados miembros.

A través del análisis de las sentencias dictadas por el T.J.U.E en 2016, y de algunas otras, se pretende poner de manifiesto cómo incide la integración europea de España en nuestro sistema jurídico. El hecho de que el ordenamiento interno y el de la Unión se dirijan a los mismos sujetos genera relación constante entre las normas europeas y las nacionales ordenadas a través de los principios de eficacia directa, primacía, cooperación leal y responsabilidad estatal en caso de incumplimiento del derecho europeo ${ }^{3}$.Un espacio supranacional donde este órgano europeo desarrolla una función de integración jurídica a través de su jurisprudencia ${ }^{4}$. De facto, muchas de las

dica se ha plasmado en las doce cuestiones prejudiciales presentadas a raíz de la Sentencia de Diego Porras. A lo anterior se sumaron las declaraciones del Presidente del Tribunal de Justicia comunitario reconociendo que no entendieron bien el problema, lo que hacía esperar un cambio de criterio en la resolución de las cuestiones prejudiciales. El anunciado cambio normativo, ante la presión de los sindicatos, se paralizó, dejando la resolución legislativa en todo caso para un futuro. ha sido un elemento que ha añadido mayor incertidumbre si cabe. Algunos autores como E. TORRECILLA: "El Tribunal de Justicia de la Unión Europea y el impacto de su reciente jurisprudencia en la regulación de la contratación temporal en España y el derecho a indemnización por extinción del contrato" en LanHarremanak. Revista de Relaciones Laborales, $\mathrm{n}^{\circ} 36,2017$, pp.18-19 apuntaban que estas resoluciones "deberán ineludiblemente conducir a una modificación de la normativa laboral y administrativa de aplicación, para evitar que se sigan produciendo decisiones judiciales como las dictadas, y también para evitar dejar en manos de la judicatura todos y cada uno de los problemas que se planteen y correr así el riesgo de interpretaciones diversas, y en más de una ocasión contradictorias, hasta llegar a la posible unificación de doctrina por parte de la Sala de lo Social del TS".

A. MANGAS MARTIN y D. LIÑAN NOGUERAS: Instituciones y Derecho de la Unión Europea, $9^{\text {a }}$ ed., Tecnos, Madrid, 2016. En el asunto Melloni, el Tribunal de Justicia afirma que, en virtud del principio de primacía del Derecho de la Unión, que es una característica esencial de su ordenamiento jurídico, la invocación por un Estado miembro de las disposiciones del Derecho nacional, aún si son de rango constitucional, no pueden afectar a la eficacia del Derecho de la Unión en el territorio de ese Estado. De modo que, en caso de contradicción, la norma estatal debe interpretarse de conformidad con la comunitaria, y si no fuera posible dejará de aplicarse en favor de aquélla. Si la contradicción no fuese evidente se deberá plantear la pertinente cuestión prejudicial ante el T.J.U.E.

En nuestro sistema, el Tribunal Constitucional, en su STC 145/2012, de 2 de julio, definía el principio de primacía como técnica o principio normativo destinado a asegurar la efectividad del Derecho Comunitario, lo que obliga a las autoridades nacionales, judiciales y administrativas, a aplicar la norma prevalente dejando sin efecto la norma interna que queda desplazada. Ya, en su Declaración $1 / 2004$, había explicado como la prevalencia no se justifica en la jerarquía sino en los distintos ámbitos de aplicación de las normas, teniendo la comunitaria la capacidad de desplazar a la otra norma que también, en principio, es válida.

Creo conveniente recordar que, respecto al principio de responsabilidad patrimonial del Estado, en el Preámbulo de la Ley 40/2015, de 1 de octubre, del Régimen Jurídico del Sector Público, se declara la novedad introducida en materia de responsabilidad patrimonial del Estado, que tendrá que responder por las lesiones sufridas por los particulares en sus bienes y derechos a causa de leyes declaradas inconstitucionales o contrarias al Derecho de la Unión Europea.

$4 \quad$ "Interesante observar cómo se ha pasado de una situación originaria de teórica separación absoluta de los respectivos ámbitos de competencia de cada uno de estos Tribunales, a una situación como la existente hoy en día, donde puede constatarse una creciente incidencia recíproca de sus respectivas jurisprudencias. Muestra ilustrativa de esta interacción es la posición del Tribunal de Justicia de las 
reformas legislativas en el ámbito laboral traen causa de la necesaria adaptación al Derecho Comunitario e inclusive la adaptación de las sentencias judiciales a la doctrina del Tribunal europeo, en aplicación del principio de primacía, le han supuesto apartarse de su doctrina anterior ${ }^{5}$. Así, por ejemplo, del bloque normativo europeo nacen las sentencias del Tribunal de la Unión que obligan al Estado español a eliminar las discriminaciones que sufren los empleados públicos temporales, al declararse la vulneración de la regulación contenida en la Directiva 1999/70/CE y en el Acuerdo Marco.

A través de la ya numerosa jurisprudencia europea se evidencia la notable labor realizada por los órganos nacionales, instancias inferiores mayoritariamente, que reclaman una mayor protección de los derechos de las personas más vulnerables en las relaciones jurídicas y, por tanto, un reequilibrio en las relaciones de poder (consumidores o trabajadores, por poner dos ejemplos). Se pone de manifiesto una posición crítica frente a las normas nacionales o frente a la interpretación que se hace desde instancias judiciales superiores, reclamando al Tribunal de Luxemburgo un control conforme al Derecho de la Unión ${ }^{6}$.

Comunidades Europeas, cuya perspectiva inicial fue la de considerar los derechos fundamentales como algo ajeno a los Tratados constitutivos de la Comunidad Económica Europea (TCEE, hoy tratado de la Comunidad Europea TCE); la subsiguiente reacción de los Tribunales Constitucionales alemán e italiano, con decisiones judiciales que manifestaban una preocupación por el respeto de los derechos fundamentales en el marco del ordenamiento jurídico comunitario; finalmente, el desarrollo por el Tribunal de Justicia de las Comunidades Europeas de una jurisprudencia que reconoció la protección de los derechos fundamentales sobre la base de los principios generales de Derecho. Otra muestra de la interacción es el instrumento utilizado para llevar a cabo la incorporación de la protección de los derechos humanos en el ordenamiento comunitario, los principios generales de Derecho comunes a los sistemas jurídicos de los Estados miembros, identificados por el Tribunal de Justicia de las Comunidades Europeas, en su jurisprudencia como el vehículo de incorporación de los valores constitucionales de los Estados Miembros", G. RODRÍGUEZ IGLESIAS, G. y A. VALLE GÁLVEZ: "El Derecho Comunitario y las relaciones entre el Tribunal de Justicia de las Comunidades Europeas, El Tribunal Europeo de Derechos Humanos y los Tribunales Constitucionales", versión española del trabajo incluido en un Manual alemán de Derecho Constitucional europeo («Handbuch des EuropáischVerfassungsrechts») dirigido por el profesor ARNOLD, editorial C. H Beck Verlag, 1997, p. 3.

Sobre el papel dinamizador del Tribunal de Justicia ver J. CRUZ VILLALÓN: "Últimas tendencias en la jurisprudencia del Tribunal de Justicia de la Unión Europea” en Temas Laborales, núm.130, 2015, pp.13-46.

5 Resulta obligado citar la Ley Orgánica 7/2015, de 21 de julio, que modificó la Ley Orgánica 6/1985, ya que en su Preámbulo ponía de manifiesto como "la progresiva internacionalización de las relaciones personales y empresariales de los ciudadanos de nuestro país exige una actualización de los criterios de atribución de jurisdicción a los tribunales españoles del orden civil", estimando la conveniencia de que en la ley se mencionase "la vinculación de los jueces y tribunales españoles al Derecho de la Unión en la interpretación que hace del mismo el Tribunal de Justicia". En este sentido, se incorporó un nuevo art. 4.bis a la L.O.P.J disponiendo que "los jueces y tribunales aplicarán el Derecho de la Unión Europea de conformidad con la jurisprudencia del Tribunal de Justicia”. Asimismo, por otra parte, la Ley 36/2011, de 10 de octubre, reguladora de la Jurisdicción Social, abre la puerta a la posibilidad de alegar sentencias europeas en recurso de casación para la unificación de la doctrina, según establece su art. 219.1\%

6 Ver el sugerente trabajo de C. MOLINA NAVARRETE: "La cuestión prejudicial y ¿El fin de los tribunales de última palabra?: Experiencias de tutela del contratante débil" en Diario La Ley, $n^{\circ}$ 9008, sección Doctrina, 26 de junio de 2017, Editorial WoltersKluwer. 
Así lo anterior, en el ámbito de la contratación temporal resulta evidente la pérdida del carácter protector del Derecho Laboral, esencial en el Estado Social, no tanto su régimen indemnizatorio como su uso abusivo y fraudulento en sectores muy concretos como las administraciones públicas. Aún, siendo necesaria en determinados ámbitos su uso generalizado no se justifica en todos los demás, en los que se recurre al encadenamiento de contratos para cubrir puestos de carácter permanente, con contratos con duración de escasos días y colocando a los trabajadores en una situación de grave precariedad. En este sentido, la Unión Europea y sus políticas sociales-laborales puede ser el motor del cambio de nuestra legislación para que vuelva a situar el epicentro en la protección de los derechos fundamentales.

\section{PRESENTACION DE LAS CUESTIONES A DEBATE: LA PÉRDIDA DEL CARÁCTER TUITIVO DEL DERECHO LABORAL}

La Constitución establece los principios básicos de la convivencia social y política. Es en la Constitución donde se consagra un conjunto de principios, directrices y derechos a partir de los que se conforman las relaciones a partir del respeto a la dignidad como fundamento del orden político y social ${ }^{7}$.

A partir de este conjunto de cláusulas reguladoras de las cuestiones sociolaborales, que integran la Constitución socio-económica, se configura nuestro sistema laboral como contexto en el que se desarrollan las relaciones de trabajo con frecuente confrontación entre los intereses profesionales de los trabajadores y los que son propios del empresariado. Nos estamos refiriendo a los arts.33, 38 y $128.1^{\circ}$ C.E. puestos en relación con el $128.2^{\circ}, 129.2^{\circ}$ y $131.1^{\circ}$ C.E, junto a los derechos derivados de los arts.7, 22, 28.1 ${ }^{\circ} \mathrm{y}$ los relativos a la acción colectiva del $28.2^{\circ}$, $37.1^{\circ}$ y $2^{\circ}$ y $129.2^{\circ}$ C.E. que son derechos fundamentales básicos de las personas en el ámbito del trabajo. Además, el derecho al trabajo (art.35) en conexión con la prohibición de discriminación y un conjunto de directrices que deben ser tenidas en cuenta en el diseño e implementación de las políticas sociales y concretamente de la política del trabajo.

Se ha hecho referencia en líneas anteriores a la cláusula del Estado Social que coloca a los poderes públicos ante el deber de materializar la Justicia Social, redistribuyendo la riqueza y las oportunidades, para poner fin a la desigualdad. Las relaciones laborales no pueden permanecer fuera de la Constitución, son relaciones del poder con un gran impacto en la vida de las personas, en su desarrollo personal e integración social, correspondiéndole al Estado compensar las desigualdades entre las partes de una relación laboral a través del Derecho del Trabajo que debe tener una finalidad tuitiva y correctora en cumplimiento del favor laboratoris como mandato

Los derechos laborales específicos (individuales y colectivos) que se han incorporado al Estatuto de los Trabajadores (E.T), los derechos fundamentales inespecíficos (M. C. PALOMEQUE LÓPEZ: "Derechos fundamentales generales y relación laboral: los derechos laborales inespecíficos" en El modelo social en la Constitución española de 1978, R. Martín Jiménez y A. Sempere Navarro (coords.), Ministerio de Trabajo e Inmigración, 2003, pp.229-248. 
constitucional (cláusula del Estado Social y su concreción en el articulado constitucional, art.9.2 $2^{\circ}$ y Capítulo III del Título I).

Por otra parte, Europa desarrolla sus políticas sociales que impactan directamente en las regulaciones de los estados miembros que han de adaptar sus modelos laborales al derecho europeo. Son numerosos los Reglamentos y las Directivas que conforman el acervo comunitario que se aplica con primacía y directamente incluso desplazando al derecho nacional si entran en contradicción, que han ido impulsando el desarrollo de las legislaciones nacionales de carácter laboral. Uno de los puntales de las políticas europeas es la protección de los trabajadores desarrollando normas tuitivas de protección de sus derechos en el marco de las relaciones laborales ${ }^{8}$.

Ahora bien, la devastadora crisis económica no ha sido respondida adecuadamente desde la Constitución, pues no se ha aplicado una perspectiva de derechos fundamentales frente a las medidas de política económica restrictivas de derechos ${ }^{9}$. Los derechos socio-económicos han sido los más afectados en beneficio de otros intereses priorizados en las políticas públicas, sufriendo notables recortes presupuestarios e intervenciones a través de Decretos-Leyes, pero también lo han sido los derechos civiles ${ }^{10}$. Uno de los derechos más afectados ha sido el derecho al trabajo a causa de los tremendos efectos de pérdida de nivel adquisitivo, caída del consumo, endeudamiento del Estado para poder hacer frente al pago de las prestaciones sociales o el incremento de las tasas de pobreza. La precarización laboral se ha agudizado, la reforma de 2012 eliminó medidas introducidas en 2010 con el objetivo de potenciar la contratación indefinida manteniéndose únicamente el sistema de bonificaciones para la contratación de personas pertenecientes a colectivos especialmente vulnerables, ya sea por razón de edad, por incapacidad, por circunstancias sociales o familiares. Los incentivos para la contratación indefinida quedaron reducidos al apo-

8 En lo que se refiere a la contratación temporal, objeto de este trabajo en buena medida, el instrumento jurídico es la Directiva 1999/70 CE, del Consejo de 28 de junio de 1999, relativa al Acuerdo Marco de la CES, la UNICE y el CEEP sobre el trabajo de duración determinada que obliga a los Estados miembros a cumplir los objetivos en ella establecidos, para lo que cada Estado llevará a cabo su transposición a su ordenamiento propio, aprobando normas nuevas o reformando las ya existentes.

9 Véase la magnífica visión global contenida en Constitutions in the Global Financial Crisis, donde el capítulo sobre España es de autoría de Agustín Ruiz Robledo. Asimismo, reviste gran interés el trabajo, circunscrito a Portugal, de M. CANOTILHO: "Austeridad y derecho constitucional: el ejemplo portugués", Democrazia\&Sicurezza, n. ${ }^{\circ}$ 1, 2016, VI. 31-71.

10 Sobre la STC 119/2014, de 16 de julio, que declara la constitucionalidad de la reforma laboral, ver P. REQUEJO: "El papel de la crisis económica en la argumentación del Tribunal Constitucional. Comentario a la STC 119/2014" en Teoría y Realidad Constitucional, UNED, núm. 36, 2015, la autora afirma que el "El Tribunal parece olvidar que su parámetro de enjuiciamiento, como el de cualquier órgano jurisdiccional, sólo puede ser normativo, debiendo dejar de lado cualquier otra razón que desvirtúe lo que ha de ser un juicio de validez, convirtiéndolo en un juicio de oportunidad", p. 430; F. BALAGUER CALLEJÓN: "Una interpretación constitucional de la crisis económica", en Revista de Derecho Constitucional Europeo, n 19, 2013, pp.449-454; F. BALAGUER CALLEJÓN.; M. AZPITARTE SÁNCHEZ; E. GUILLÉN LÓPEZ y J. F. SÁNCHEZ BARRILAO: El Impacto de la Crisis Económica en las Instituciones de la UE y los Estados Miembros, Thomson Reuters Aranzadi, 2015. 
yo de nuevos emprendedores, circunscrito a un perfil muy determinado, y a la transformación en indefinidos de los contratos temporales de prácticas, para la formación, aprendizaje, de relevo o de sustitución ${ }^{11}$.

Así las cosas, consideramos que se ha roto la base constitucional. En los últimos tiempos hemos asistido a la transformación del sistema tuitivo frente a las críticas de rigidez que obstaculizan la contratación o impiden la competitividad en este mundo globalizado ${ }^{12}$. Se han aprobado sucesivas reformas laborales que han resquebrajado el sistema de protección social, se ha replegado el marco de protección con un daño evidente para los derechos de los trabajadores que han sufrido una rebaja de los estándares de protección a través de la desregulación o del establecimiento de convenios. Así, principios básicos como la estabilidad del empleo, tutelador de los trabajadores frente a decisiones empresariales extintivas del contrato de trabajo, o las políticas de fomento de la contratación indefinida frente a la contratación temporal, se han ido debilitando frente al desarrollo de políticas legislativas que han flexibilizado la normativa laboral ${ }^{13}$. La flexiseguridad ${ }^{14}$ y la desregulación legislativa, inciden directamente en el modelo de contratación y en las formas de extinción de

11 Las reformas datan de 2010, 2011 y 2012, siendo la de 2012 la que más ha afectado al Estatuto de los Trabajadores reformando la contratación, el despido y la negociación colectiva. En materia de despido, en 2010 se flexibilizaron las causas objetivas del despido y en 2012 se aprobó su abaratamiento. Sobre las reformas laborales ver J. PÉREZ INFANTE: "Las reformas laborales en la crisis económica: su impacto económico" en Ekonomiaz, $\mathrm{n}^{\circ} 87,1^{\circ}$ semestre, 2015, pp. 1-36.

12 J. L. MONEREO PEREZ: "La racionalización jurídica de las relaciones laborales y la emergencia de nuevas fuentes reguladoras en el orden internacional" en Lex Social, vol. 8, $\mathrm{n}^{\circ} 1$, 2018, pp.1-44.

13 Están en la memoria de todos nosotros las políticas públicas aprobadas en los últimos años que han introducido profundas reformas legislativas. La reforma de la legislación laboral, los recortes salariales, los recortes de las pensiones y la pérdida generalizada de los derechos sociales.

14 Este modelo se desarrolla en Dinamarca y se denomina así por el sociólogo Adriansenns que la define como el conjunto de políticas capaces de conciliar las medidas de flexibilidad con acciones de seguridad, cuyos beneficiarios habrían de ser precisamente los trabajadores afectados por aquellas primeras. Se conjugan la flexibilidad del mercado y la protección o seguridad de los trabajadores, difícil cometido, pues se tendría que flexibilizar el despido "eliminando o reduciendo las barreras legales con que se protegía al trabajador, pero se expande la protección de sus ingresos y las oportunidades de encontrar rápidamente un nuevo trabajo mediante las políticas pasivas (subsidios o prestaciones) y activas (capacitación, servicios de colocación) a cargo de la seguridad social y del propio Estado", Derecho PUCP, $n^{\circ}$ 68, 2012, pág.7. En este sentido, se expresa la Exposición de Motivos de la Ley $3 / 2012$, cuando dice que se pretende garantizar tanto la flexibilidad de las empresas en la gestión de los recursos humanos como la seguridad de los trabajadores en el empleo y la consecución de adecuados niveles de protección social.

En Europa el informe publicado como Libro Verde, "Modernizar el derecho laboral para afrontar los retos del siglo XXI",COM (2006) 708 final, 22 de noviembre de 2006; Comunicación de la Comisión al Parlamento Europeo, al Consejo, al Comité Económico y Social Europeo y al Comité de las Regiones, "Hacia los principios comunes de la flexiseguridad: más y mejor empleo mediante la flexibilidad y la seguridad", donde se dice que se requiere un mercado más flexible para reducir la segmentación del mercado de trabajo, lo que se consigue sustituyendo la seguridad en el puesto de trabajo por seguridad en el empleo y permitir que las empresas puedan adaptar la mano de obra a las necesidades económicas cambiantes. A. BAYLOS GRAU y J. PÉREZ REY: 
la relación laboral, rebajando las obligaciones sociales del empresariado con el fin de fomentar la contratación, que será temporal, resultando más fácil despedir a los trabajadores. El resultado directo es el fin de la estabilidad laboral y regresión de los derechos sociales fundamentales ${ }^{15}$.

El argumento de su necesidad para fomentar el empleo en épocas de graves crisis no se sostiene una vez constatada su incapacidad para la creación de empleo ya que ni siquiera se contuvo la destrucción de puestos de trabajo que asoló a nuestras sociedades. Lo anterior nos coloca ante la necesidad de recordar que las normas constitucionales en ningún caso pueden ser incumplidas cuando se regula el despido, el derecho al trabajo $^{16}$, la estabilidad en el empleo y la protección de los trabajadores (contra el despido improcedente o nulo $)^{17}$. Y esto es lo que ha ocurrido con la generalización de la contratación temporal convertida en regla frente a su justificación como medida excepcional tanto en épocas de crecimiento como de crisis económica, a modo de herramienta de flexibilización del mercado. Las consecuencias de este modelo de contratación pueden resumirse en una mayor precarización del empleo, sobre todo en los sectores menos cualificados y entre la población femenina, por no contribuir a la estabilidad laboral, no responder al pleno empleo y no dar derecho al cobro de prestaciones dignas.

"Sobre el Libro Verde: modernizar el derecho laboral para afrontar los retos del siglo XXI", Cuadernos de la Fundación Sindical de Estudios, núm. 5, 2006.

15 Resulta ilustrativo establecer diferentes modelos europeos sobre el despido laboral. Por una parte, encontramos los países de norte de Europa, con una regulación flexible del despido, pero que ofrecen como contrapartida prestaciones elevadas, además de contar con políticas activas de reintegración en el empleo. En segundo lugar, los países anglos donde resulta fácil el despido sin que exista una normativa de protección, pero si cuentan con políticas de activación de las personas desempleadas. Por lo que respecta a los países del sur de Europa, las normas protegen a los trabajadores frente al despido con prestaciones de desempleo limitadas y donde no existen potentes políticas de empleo. En cuanto a los países centroeuropeos, se suele poner el ejemplo de Alemania donde la norma protege frente a los despidos con prestaciones importantes y con políticas desarrolladas.

La intervención pública se ha replegado a favor de la intervención de la autonomía privada y esta flexibilización lleva a una progresiva desprotección de los trabajadores, al primar los resultados económicos y productivos sobre los derechos fundamentales, produciéndose una efectiva regresión de los derechos sociales fundamentales. A. ABA CATOIRA: "La efectividad de los derechos de los trabajadores y del empresariado desde la implantación de las tecnologías en el ámbito laboral" en Anuario de la Facultad de Derecho da Universidade da Coruña, n 18, 2014, pp.79-106; "Los derechos de la generación electrónica en el ámbito laboral” en Revista de Derecho, nº 12, 2011, pp.257-281; “Art. 28: Derechos de acción colectiva. Sindicación y Huelga” en A. TUNES (coord.) en Derechos Fundamentales: Aspectos básicos y actuales, Andavira, Santiago de Compostela, 2017, pp.539-566.

16 STC 22/1981, de 2 de julio de 1981, declara que "el derecho al trabajo no queda limitado a la libertad de trabajar, sino que implica algo más: conlleva el derecho a un puesto de trabajo y, en este sentido, adoptaría una doble faceta. Por un lado -faceta individual concretada en el artículo 35.1 CE-, implicaría el derecho de todas las personas que acrediten la capacidad exigida para ello a un determinado puesto de trabajo y el derecho a la estabilidad en el empleo, esto es, a no ser despedido sin la concurrencia de causa justa. Por otro -faceta colectiva que emana del artículo 40.1-, supondría un mandato dirigido a los poderes públicos para que realicen una política de pleno empleo".

17 La STC 23/1994, de 27 de enero, declara que la inexistencia de una reacción adecuada contra el despido o cese debilitaría peligrosamente la consistencia del derecho al trabajo y vaciaría al derecho que lo regula de su función tuitiva". 
Así las cosas, la reforma de la legislación laboral debe seguir la senda de protección que nunca debió haber abandonado, siendo posible flexibilizar la contratación sin desproteger a los trabajadores. Es evidente la necesaria reforma del Estatuto de los Trabajadores ${ }^{18}$ para adecuarlo a la realidad española y también a la realidad europea, pues el derecho interno se transforma por la transposición e incorporación del Derecho de la Unión Europea y la doctrina del T.J.U.E.

Es en este punto donde se hace evidente la función de los órganos jurisdiccionales como garantes de los derechos, poniendo de manifiesto como la normatividad constitucional obliga a su cumplimiento en cualquiera que sea el contexto, económico o financiero, de aplicación. A través de las decisiones de los tribunales, principalmente, el Tribunal Supremo y el Tribunal Constitucional, se controla el ejercicio del poder y la efectividad de los derechos fundamentales. No obstante, no siempre hay conformidad de todos los órganos judiciales con la legislación o con la interpretación que se hace desde "arriba". Y aquí, es donde la cuestión prejudicial aparece como una vía de control de la legalidad española, pidiéndole los órganos judiciales españoles al tribunal europeo que establezca una interpretación conforme al Derecho Comunitario ${ }^{19}$, poniendo de manifiesto un activismo del Tribunal de Luxemburgo que ha convulsionado el panorama jurídico español, básicamente en el mercado de crédito hipotecario ${ }^{20} \mathrm{y}$ en el mundo de las relaciones laborales ${ }^{21}$.

Es al T.J.U.E a quien corresponde garantizar la debida interpretación y aplicación de los Tratados (art. 19.1 $1^{\circ}$ TUE), por lo que "se pronunciará (...): a) sobre los recursos interpuestos por un Estado miembro, por una institución o por personas físicas o jurídicas; b) con carácter prejudicial, a petición de los órganos jurisdiccionales nacionales, sobre la interpretación del Derecho de la Unión o sobre la validez de los actos adoptados por las instituciones; c) en los demás casos previstos por los Tratados" (art. 19.3 $3^{\circ} \mathrm{TUE}$ ).

El principio de eficacia directa implica que el Derecho de la Unión tiene plenos efectos en todos los estados miembros desde que entra en vigor generando derechos y obligaciones, de modo que, cuando las normas nacionales presenten contradicciones con una Directiva, deben ser interpretadas por los tribunales nacionales de forma que prevalezca el derecho comunitario. En este orden de cosas, la Ley Orgánica 7/2015, de 21 de julio, modificó la Ley Orgánica del Poder Judicial añadiendo el artículo 4 bis que establece que "Los Jueces y Tribunales aplicarán el derecho de la Unión Europea de conformidad con la jurisprudencia del Tribunal de Justicia Europeo".

En la S.T.J.U.E de 26 de febrero de 2013, C-399/11, se declaró que "en virtud del principio de primacía del Derecho de la Unión Europea, que es una característica

18 Texto refundido de la Ley del Estatuto de los Trabajadores, aprobado mediante el Real Decreto Legislativo 1/1995, de 24 de marzo (BOE $n^{\circ} .75$, de 29 de marzo de 1995).

19 Art. $267.2^{\circ}$ y $3^{\circ}$ T.U.E.

20 Sentencia de 21 de diciembre de 2016, asuntos acumulados C-307/15 y C-308/15, Ana Maria Palacios Martínez/banco Bilbao Vizcaya Argentaria, S.A, Banco Popular, S.A/Emilio Irles López y Teresa Torres Andreu. Tras esta S.T.J.U.E la Sala de lo Civil del Tribunal Supremo ha rectificado toda su jurisprudencia, STS, Sala Primera, 123/2017, de 24 de febrero.

21 Sentencia de 14 de septiembre de 2016, asunto C-596/14, De Diego Porras vs Mnisterio de Defensa. 
esencial del ordenamiento jurídico de la Unión, la invocación por un estado miembro de las disposiciones del Derecho nacional, aún si son de rango constitucional, no pueden afectar a la eficacia del Derecho de la Unión en territorio de ese Estado".

En caso de no ser posible interpretar la norma nacional de conformidad con la comunitaria esa incompatibilidad debe ser apreciada por el Juez quien, en caso de duda, debe elevar la cuestión prejudicial ante el Tribunal de Justicia. Como ha dicho nuestro Tribunal Constitucional, la cuestión prejudicial es un instrumento que sirve para depurar el ordenamiento jurídico, por eso en caso de duda, en supuestos de aplicación del Derecho Comunitario, el Juez o Tribunal interno podrá plantear su duda al Tribunal de Justicia (STC 58/2004, FJ $10^{\circ}$ ). Por último, cumple recordar que las sentencias del T.J.U.E de 2016 no declararon la invalidez de las actuaciones nacionales, pero si exigían del Estado la adopción de "las medidas necesarias para la ejecución de la sentencia del Tribunal" (art. 260.1 ${ }^{\circ}$ T.F.U.E) que declaraban el incumplimiento del derecho europeo por el estado español.

\section{SUPUESTOS ANALIZADOS POR EL TRIBUNAL DE JUSTICIA}

Una de las sentencias que se dictaron por el T.J.U.E el 14 de septiembre de 2016, asunto C-596/14, resolvió la cuestión prejudicial formulada por el Tribunal Superior de Justicia de Madrid, por la que sometía a su juicio la interpretación de la Directiva1999/70,exclusivamente en lo concerniente a la conformidad de la legislación española en materia de indemnización por la extinción de contrato de los trabajadores temporales, sin plantear dudas sobre la legalidad del llamado contrato de interinidad ${ }^{22}$. En concreto, la cuestión que se plantea es si la extinción del contrato de interinidad, a causa de su finalización, genera el derecho a percibir indemnización y si el art. 49. c) del E.T incumple la normativa europea respecto al principio de igualdad. Por tanto, si cabe equiparación entre la finalización del contrato temporal por causas lícitas con la extinción por causas objetivas de los contratos fijos, lo que daría derecho al cobro de la indemnización prevista para las extinciones por causas objetivas, es decir, de 20 días por año trabajado.

La Sra. Ana de Diego había sido contratada por el Ministerio de Defensa como interina en febrero de 2003 para cubrir el puesto de trabajo de una liberada sindical con contrato suspendido durante siete años. En virtud del Real Decreto-Ley20/2012, se redujo el número de liberados sindicales en el ámbito del sector público estatal, lo que supuso la reincorporación de la trabajadora sustituida a su puesto de trabajo y la consiguiente extinción de la relación laboral sin reconocérsele derecho a cobrar

22 Se somete a interpretación del Tribunal comunitario la cláusula 4 del Acuerdo marco sobre el trabajo de duración determinada, celebrado el 18 de marzo de 1999, que figura en el anexo de la Directiva 1999/70/CE del Consejo, de 28 de junio de 1999, relativa al Acuerdo marco de la CES, la UNICE y el CEEP sobre el trabajo de duración determinada (DO 1999, L 175, p. 43). Esta Directiva es muy breve y muy clara. En su Preámbulo destaca la preeminencia de la contratación indefinida como "forma más común de relación laboral" salvo en determinadas situaciones en que procede la contratación temporal porque "responden en ciertas circunstancias, a las necesidades de los empresarios y de los trabajadores". 
indemnización alguna. Por todo ello, la trabajadora afectada demandó al Ministerio de Defensa alegando fraude de ley en su contratación y, tras la desestimación de su pretensión en primera instancia, recurrió ante el Tribunal Superior de Justicia de Madrid que, tras declarar la suspensión del procedimiento, elevó cuatro cuestiones prejudiciales ante el T.J.U.E.

Las otras dos sentencias dictadas en ese día, C-16/15 y C-184/15 y C-197/15 también resolvieron sendas cuestiones prejudiciales. En la interpuesta por el Juzgado de lo Contencioso-Administrativo número4 de Madrid se abordaba el recurso presentado por una enfermera que, tras ser nombrada personal estatutario temporal eventual en el Hospital Universitario de Madrid "para realizar servicios determinados de naturaleza temporal, coyuntural o extraordinaria", se mantuvo en esta situación desde el 5 de febrero de 2009 hasta el 31 de marzo de 2013 a través de sucesivos contratos temporales que se le fueron renovando con base al art. 9 de la Ley $55 / 2003^{23}$.

En la última de las referenciadas, C-184/15 y C-197/15, asuntos acumulados, Sra. Martínez Andrés vs Servicio Vasco de Salud y Sr. Castejana López vs. Ayuntamiento Vitoria-Gasteiz se aborda la protección jurídica frente a la utilización abusiva de la contratación o relaciones de servicio temporales en el ámbito de las administraciones públicas y el diferente grado de protección que disfrutan frente al personal contratado laboral.

\subsection{Indemnizaciones laborales ante la extinción de la relación laboral ${ }^{24}$}

La cuestión prejudicial resuelta por la Sentencia De Porras se centra en la adecuación de la legislación española a la norma comunitaria, en lo referente a la regulación de las indemnizaciones por extinción del contrato.

Las dudas elevadas por el Tribunal Superior de Justicia de Madrid fueron las siguientes:

(1) Si la indemnización por finalización del contrato temporal está comprendida en las condiciones de trabajo de la cláusula 4 apartado $1^{\circ}$ del Acuerdo Marco, que establece que "por lo que respecta a las condiciones de trabajo, no podrá tratarse a los trabajadores con un contrato de duración determinada de una manera menos favorable que a los trabajadores fijos comparables

23 El desempeño del puesto se realizó ininterrumpidamente, desde febrero de 2009 hasta junio de 2013 a través de contratos sucesivos, pero, al ser personal sometido al régimen estatutario no disfrutaba de las condiciones que le corresponderían si lo fuese en virtud de una relación contractual laboral regulada en el Estatuto de los Trabajadores.

${ }^{24}$ Por todos, M. RODRÍGUEZ-PIÑERO Y BRAVO-FERRER, Mª E. CASAS BAAMONDE: "La igualdad de trato en la contratación temporal, el derecho de los trabajadores interinos a indemnización por la finalización de su contrato por "causa objetiva", y los encadenamientos abusivos de contratos y relaciones de servicios temporales en las Administraciones Públicas españolas. Las sentencias del Tribunal de Justicia de la Unión Europea de 14 de septiembre de 2016" en Derecho de las Relaciones Laborales, no 9, 2016 y M.C. PALOMEQUE LÓPEZ, "Tres sentencias que estremecieron al mundo", en Trabajo y Derecho, n 23, 2016. 
por el mero hecho de tener un contrato de duración determinada, a menos que se justifique un trato diferente por razones objetivas".

(2) En caso afirmativo, si la indemnización ha de ser la misma en supuestos de extinción por causas objetivas tanto para los trabajadores con un contrato cuya finalización está determinada por condiciones objetiva como para los que tienen contrato de duración indefinida.

(3) Si se concluye que tienen derecho a la misma indemnización, si el art.49.1 ${ }^{\circ} \mathrm{c}$ ) del E.T debe interpretarse conforme a la Directiva 1999/1970 o contrario a esta norma por introducir una discriminación. La norma nacional establece que la finalización del contrato de interinidad por llegar a su término "no comporta el abono de ninguna indemnización" mientras que "la extinción de un contrato por causas objetivas genera el abono de una indemnización de veinte días de salario por año de servicio" (artículo 52 E.T).

(4) En la cuestión no se distinguen las distintas situaciones jurídicas que se pueden dar en el ámbito de la interinidad, pues sí existe derecho a la indemnización establecida para los contratos temporales cuando la finalización responde a causas objetivas, pero no se reconoce ese derecho cuando la extinción obedece a su finalización. Esto permite concluir que las diferencias se introducen en dos sentidos, frente a los demás temporales y frente a los indefinidos.

En definitiva, los trabajadores fijos al finalizar su contrato tienen derecho a cobrar el equivalente al salario de 20 días por año trabajado; los temporales 12 días por año, pero, si son interinos, no tienen derecho a percibir cantidad alguna. La Sala del Tribunal Supremo estima que la diferencia de trato entre el contrato de obra y servicio y el eventual, respecto del contrato de interinidad, estriba en que la extinción de éste último no implica la extinción del puesto de trabajo porque hay una reincorporación, mientras que esto no sucede en las otras modalidades de contratación temporal.

La interpretación que hace el órgano comunitario de la Directiva europea resuelve las cuestiones planteadas por el órgano jurisdiccional español en los siguientes términos:

(1) La cláusula 4, apartado 1, del Acuerdo marco sobre el trabajo de duración determinada que figura en el anexo de la Directiva 1999/70/CE del Consejo, de 28 de junio de 1999, relativa al Acuerdo marco de la CES, la UNICE y el CEEP sobre el trabajo de duración determinada, incluye en las condiciones de trabajo "la indemnización que un empresario está obligado a abonar a un trabajador por razón de la finalización de su contrato de trabajo de duración determinada".

(2) La cláusula 4 del Acuerdo marco sobre el trabajo de duración determinada, se debe interpretar como contraria a la norma española que deniega cualquier indemnización cuando se extingue un contrato de interinidad, mientras que reconoce este derecho a los trabajadores fijos en situación comparable cuando se extingue su contrato por causas objetivas ${ }^{25}$. Si no cabe introducir diferencias de

25 La situación comparable queda definida de manera general en el apartado 40 "(para) apreciar si las personas de que se trata ejercen un trabajo idéntico o similar, en el sentido del Acuerdo marco, debe comprobarse si, habida cuenta de un conjunto de factores, como la naturaleza 
trato en las condiciones de trabajo en atención a la duración del contrato, la norma española resulta incompatible con el principio de igualdad y la prohibición de no discriminación. El mero hecho de que un trabajador preste sus servicios, en virtud de un contrato de interinidad, no justifica la negativa de su derecho a la mencionada indemnización (Asunto de Diego Porras, C-596/2014).

El principal argumento de la sentencia sostiene que la extinción del contrato por causas objetivas (despido objetivo con la misma indemnización para fijos y temporales) y la extinción del contrato de trabajadores temporales interinos por el cumplimiento de la condición a la que está sometido (en el caso concreto la incorporación de la trabajadora sustituida) merecen el mismo tratamiento jurídico. En consecuencia, tras la finalización del contrato, si un trabajador interino realiza las mismas funciones que aquél al que sustituye, tendrá derecho a la misma indemnización que cobra el trabajador indefinido. Como a nadie se le oculta, la resolución judicial comunitaria convulsionó el sistema de relaciones laborales, afectando directamente a los trabajadores interinos, pues, la mera temporalidad no justifica, sin más, la diferencia indemnizatoria ${ }^{26}$. No obstante, y de modo excepcional, cabe una diferencia de trato si existen razones objetivas que la justifiquen, a saber: "la especial naturaleza de las tareas para cuya realización se celebran los contratos de duración determinada y en las características inherentes a las mismas o, eventualmente, en la persecución de un objetivo legítimo de política social por parte de un Estado miembro".

Como se aprecia, este fallo judicial incide directamente, a su vez, sobre varias cuestiones:

(1) Si se puede aplicar a todos los contratos temporales, pues el caso que da lugar a este pronunciamiento es muy concreto, con la demandante trabajando para la administración pública como interina hasta la extinción de su contrato por incorporación de la trabajadora sustituida una vez reducidos los liberados sindicales.

(2) Si tiene efectos retroactivos, pues hay que determinar si se aplica a todos los contratos temporales vigentes y a los firmados a partir de este momento o también a los extinguidos en un tiempo anterior a la sentencia.

del trabajo, los requisitos de formación y las condiciones laborales, puede considerarse que estas personas se encuentran en una situación comparable", ver Sentencia de 18 de octubre de 2012, Valenza y otros, C-302/11 a C-305/11.

26 Esta doctrina comunitaria tiene efectos en todas las legislaciones nacionales que regulan como figuras jurídicas distintas a los trabajadores fijos y los trabajadores temporales. En este orden de cosas, la normativa española no parece ser la menos garantista de la Unión Europea, pues, a diferencia de otros estados miembros, reconoce este derecho a los trabajadores temporales en cuantía de 12 días por año trabajado en los contratos de obra, servicios, eventuales y por circunstancias de la producción. En Alemania, ejemplo de economía desarrollada, no hay protección legal frente al despido en contratos temporales, pero, la firma de estos contratos está muy reducida por la obligación de justificarla en causa objetivas, teniendo como máximo una duración de dos años. En Francia, existe un régimen jurídico más protector, ya que la contratación temporal sólo cabe en circunstancias limitadas y con una duración máxima de 18 meses, salvo para la sustitución de empleados y con una indemnización del $10 \%$ de la remuneración bruta pagada durante el contrato. 
(3) Si debe reformarse el Estatuto de los Trabajadores para dar un tratamiento conjunto a la nueva situación o, si, por el contrario, la aplicación de la sentencia debe dejarse a los tribunales en función de las singularidades declaro concreto.

(4) En caso de abordarse la reforma de la ley si se debe reconocer el derecho de los trabajadores interinos a cobrar la indemnización por extinción de la relación laboral, en términos equivalentes a la prevista para el despido objetivo, independientemente de la fecha de celebración del contrato, o se debe incluir a todos los trabajadores temporales.

A partir de la Sentencia de referencia, los Tribunales Superiores de Justicia han aplicado directamente la doctrina en ella contenida, salvo alguna excepción como la Sentencia del Tribunal Superior de Justicia de Cataluña de 30 de diciembre de 2016, alegando que no se había planteado esta cuestión por las partes sin que sea posible estimarla de oficio.

Por otra parte, quedaría por clarificar si esta doctrina resulta aplicable a las relaciones laborales entre particulares, dado que las sentencias de los Tribunales Superiores de Justicia han concluido de modo diferente. Las sentencias de 16 de noviembre de 2016 dictadas por el Tribunal Superior de Justicia de Andalucía y las de su homónimo vaco de 18 de octubre del mismo año. El Tribunal andaluz sostiene que las Directivas no tienen efectos en las relaciones entre particulares, excepto en materia antidiscriminatoria, correspondiéndoles una indemnización de doce días de salario por año trabajado, abriéndose la puerta a procesos contenciosos-administrativos en reclamación de responsabilidades a la administración, por haber transpuesto defectuosamente la norma comunitaria de aplicación. Por otra parte, el Tribunal vasco sique reconoció la indemnización de veinte días de salario por año trabajado, defendiendo la aplicación directa de la Directiva y del pronunciamiento del T.J.U.E entre particulares, por tratarse de una concreción del principio de no discriminación consagrado en el art. $21.1^{\circ} \mathrm{de}$ la C.D.F.U.E que se puede invocar directamente entre particulares ${ }^{27}$.

\subsection{El encadenamiento de contratos temporales}

En su sentencia de 14 de septiembre de 2016, asunto Pérez López, C-16/15, el T.J.U.E analiza la normativa europea y la española para dirimir el conflicto sobre la interpretación de las cláusulas 3, 4 y 5, del Acuerdo marco sobre el trabajo de duración determinada, ya citado $^{28}$. La normativa interna analizada son el art. 9 de la Ley 55/2003, el art. $15.3^{\circ}$ y $49.1^{\circ}$.c) del E.T que establecen la presunción de considerar indefinidos los contratos temporales celebrados en fraude de ley y la regulación de la indemnización de determinados contratos de duración determinada, respectivamente, así como el desarrollo que del art. 15 se hace en el Real Decreto 2720/1990, de 18

27 Al respecto, P. MENENDEZ SEBASTIAN: "Inaplicación horizontal de la doctrina de Diego Porras. Comentario a la sentencia de 16-11-2016, rec.1439/2016, del TSJ Andalucía-Málaga" en Revista de Información Laboral, n¹2, 2016, pp. 153-165.

28 Ya con anterioridad las sentencias de 26 de enero de 2012, asunto Kücük, C-586/10; de 13 de marzo de 2014, asunto Márquez Samohano contra la Universitat Pompeu Frabra. 
de noviembre, estableciendo que el contrato eventual está pensado para responder a necesidades coyunturales.

La institución comunitaria declara que el órgano judicial nacional (que promueve la cuestión prejudicial) deberá comprobar si la norma nacional controvertida, en base a la cual se produce la renovación de nombramientos de duración determinada en el ámbito de los servicios de salud, supone alguna de las medidas comprendidas en la cláusula 5, apartado 1 del Acuerdo marco, en cuanto razones objetivas que justifican la renovación de contratos o de relaciones laborales de duración determinada. Sin embargo, acto seguido, se restringe toda posibilidad de justificar la renovación para "el desempeño de modo permanente y estable de funciones de los servicios de salud incluidas en la actividad normal del personal estatutario fijo". Y así lo determina al entender que, de otro modo, se estaría contraviniendo la finalidad del Acuerdo Marco que no es otra que "los contratos de trabajo de duración indefinida constituyan la forma más común de relación laboral" 29.

En la sentencia dictada en el asunto Pérez López/Servicio Madrileño de Salud, se resuelve, según hemos anticipado, la cuestión prejudicial planteada por el Juzgado de lo Contencioso número 4 de Madrid solicitando aclaración sobre la adecuación de la Ley 55/2003 al Acuerdo Marco sobre duración determinada que establece que "1. Por razones de necesidad, de urgencia o para el desarrollo de programas de carácter temporal, coyuntural o extraordinario, los servicios de salud podrán nombrar personal estatutario temporal [...] de interinidad, de carácter eventual o de sustitución. 2 . El nombramiento de carácter interino se expedirá para el desempeño de una plaza vacante de los centros o servicios de salud, cuando sea necesario atender las correspondientes funciones. Se acordará el cese del personal estatutario interino cuando se incorpore personal fijo, por el procedimiento legal o reglamentariamente establecido, a la plaza que desempeñe, así como cuando dicha plaza resulte, amortizada. 3 . El nombramiento de carácter eventual se expedirá: a) cuando se trate de la presta-

29 El uso abusivo de la contratación temporal ha llevado a una desvirtualización de esta figura concebida para cubrir necesidades no permanentes. Algo se ha mejorado con el art. $15.5^{\circ} \mathrm{del}$ E.T y el art. 70 del E.B.E.P tras el Real Decreto Legislativo 5/2015, de 30 octubre, por el que se aprueba el texto refundido de la Ley del Estatuto Básico del Empleado Público, que ahora reza así: "Las necesidades de recursos humanos, con asignación presupuestaria, que deban proveerse mediante la incorporación de personal de nuevo ingreso serán objeto de la oferta de empleo público, o a través de otro instrumento similar de gestión de la provisión de las necesidades de personal, lo que comportará la obligación de convocar los correspondientes procesos selectivos para las plazas comprometidas y hasta un diez por cien adicional, fijando el plazo máximo para la convocatoria de los mismos. En todo caso, la ejecución de la oferta de empleo público o instrumento similar deberá desarrollarse dentro del plazo improrrogable de tres años". A partir de esta modificación legislativa se han ido convirtiendo, vía judicial, en trabajadores indefinidos todos aquellos temporales con más de tres años ocupando la plaza.

M. J. RODRÍGUEZ CRESPO: "Límites al uso abusivo de la contratación temporal por parte de las Administraciones Públicas. Un análisis a la luz de los recientes pronunciamientos del T.J.U.E: asuntos maría Elena López contra el Servicio Madrileño de Salid y Martínez Andrés (C16/15) y Otro contra el Servicio Vasco de Salud (C-184/15) en Revista de Información Laboral, $\mathrm{n}^{\mathrm{o}}$ 4, 2017, pp. 57-69. 
ción deservicios determinados de naturaleza temporal, coyuntural o extraordinaria) Cuando sea necesario para garantizar el funcionamiento permanente y continuado de los centros sanitarios; c) Para la prestación de servicios complementarios de la reducción de una jornada ordinaria".

En Luxemburgo se entiende que las necesidades que las administraciones públicas presentan en determinados ámbitos como la enseñanza o la sanidad se pueden interpretar como razones objetivas cuando se trata de sustituir a trabajadores que no están disponibles por determinadas causas, de manera que pueden ser sustituidos temporalmente de forma sucesiva. Asimismo, se ha permitido que las Universidades recurran a este tipo de contratación a través de profesorado asociado en cuanto profesionales de reconocida competencia que ofrecen una especialización beneficiosa para la enseñanza, siempre que sea una necesidad provisional sin que pueda prorrogarse para un desempeño permanente y duradero. Esta interpretación impide la formalización sucesiva de contratos de duración determinada en aquellos supuestos abusivos en los que se recurre a esta modalidad para cubrir necesidades permanentes y duraderas. Serán las autoridades nacionales las que tendrán que adoptar las medidas necesarias para evitar abusos derivados de la contratación sucesiva por tiempo determinado que conducen a la precarización y a la inestabilidad laboral tan habitual en el sector público español, regulando las razones objetivas que justifiquen la necesidad de la renovación, su duración y el número máximo posible.

Por tal motivo, la norma española objeto de controversia, el art. 9 de la Ley 55/2003 del Estatuto del Personal Estatutario de los Servicios de Salud, se declara contrario a la cláusula 5 del Acuerdo marco, porque permite la renovación de contratos de duración determinada sin que existan situaciones coyunturales sino permanentes y estables de personal cualificado. El Tribunal de Justicia no diferencia entre los trabajadores que cubren vacantes de funcionarios y aquellos otros que cubren vacantes de personal laboral reconociéndoles a todos ellos la condición de indefinidos no fijos ${ }^{30}$.

Por último, referir que la tercera de las sentencias relacionadas se pronuncia sobre las cuestiones suscitadas por la Sala de lo Contencioso-Administrativo del Tribunal Superior de Justicia del País Vasco en relación a dos asuntos acumulados (C-184/15 y C-197/15) siendo demandados el Servicio Vasco de salud y el Ayuntamiento de Vitoria respectivamente. En el primero la actora presta servicios como personal estatutario temporal eventual y en el segundo la relación es a través de un contrato de duración determinada. Se solicita a la instancia europea que establezca si hay vulneración del Acuerdo Marco ante el hecho de que estas dos categorías jurídicas no tengan derecho a mantenerse como indefinidos no fijos en caso de abuso en su contratación temporal, equiparándose a los contratados laborales. Para el Tribunal nacional siguiendo la doctrina europea (será el tribunal nacional quien tendrá que averiguar si las administraciones utilizan abusivamente estas modalidades de contratación) en ambos casos resulta de aplicación la Directiva 1999/70/CE porque

30 La otra sentencia del Tribunal de Justicia comunitario sobre estos extremos de la contratación temporal fue dictada en los asuntos acumulados C-184/15, Martínez Andrés/Servicio Vasco de Salud y C-197/15, Castejón López/Ayuntamiento de Vitoria. 
hay una clara utilización abusiva de la contratación temporal, no debiendo aplicarse una diferente protección según la naturaleza jurídica de la relación que vincula a la persona trabajadora con la Administración.

\section{DETERMINACIÓN DE LA BASE DE CÁLCULO DE LA PRESTACIÓN}

Por otra parte, hemos de recordar que hay otros asuntos laborales que presentan dudas de adecuación entre las normas nacionales y las normas comunitarias. La STJUE de 9 de noviembre de 2017, dictada en el asunto C-98/15, resuelve la cuestión prejudicial planteada por el Juzgado de lo Social n ${ }^{\circ} 33$ de Barcelona, mediante resolución de 6 de febrero de 2015. La duda judicial se plantea en el procedimiento que enfrenta a la trabajadora demandante y al Servicio Público de Empleo Estatal (SPEE) relativo a la determinación de la base de cálculo de la duración de la prestación por desempleo para los trabajadores a tiempo parcial de tipo vertical. El tribunal nacional solicita al órgano europeo que interprete la cláusula 4 del Acuerdo Marco sobre el trabajo a tiempo parcial, que figura en el anexo de la Directiva 97/81/CE del Consejo, de 15 de diciembre de 1997 y el art. 4 de la Directiva 79/7/CEE del Consejo, de 19 de diciembre de 1978, relativa a la aplicación progresiva del principio de igualdad de trato entre hombres y mujeres en materia de seguridad social; una duda que surge ante la exclusión que realiza la norma nacional de los períodos de cotización correspondientes a los días no trabajados, en la determinación de la duración de la prestación.

La actora trabajó como limpiadora a tiempo parcial de manera ininterrumpida desde el 23 de diciembre de 1999 hasta el 29 de julio de 2013 con una jornada laboral de dos horas y media, los lunes, miércoles y jueves de cada semana y cuatro horas el primer viernes de cada mes. Una vez extinguida su relación laboral se le concedió prestación por desempleo de 420 días por lo que interpuso demanda judicial impugnando las liquidaciones individuales efectuadas por el SPEE, al considerar que trabajó durante seis años consecutivos, cotizando por 30 o 31días al mes, teniendo derecho a una prestación de 720 días en lugar de los 420 días reconocidos. Se alega que la exclusión de los días no trabajados, a los efectos del cálculo de su prestación por desempleo, introduce una diferencia de trato en detrimento de los trabajadores a tiempo parcial de tipo vertical ${ }^{31}$.

En la cuestión prejudicial se señala que la demandante cotizó durante la totalidad de los seis años anteriores a la extinción de su relación laboral y que las cotizaciones, de carácter mensual, se calcularon basándose en el salario que se percibe por un mes completo (es decir, por 30 o 31días) y no por horas o días trabajados. La norma sólo permite contabilizar los días trabajados y no todo el período de cotización para determinar la duración de la prestación por desempleo. Por lo anterior, el tribunal remitente considera que esta categoría de trabajadores está doblemente

31 La modalidad de trabajo a tiempo parcial vertical es aquella en la que se concentran las horas de trabajo en determinados días laborables frente al horizontal donde se trabaja todos los días laborables de la semana. 
penalizada, ya que, siendo a tiempo parcial, el salario es menor y también lo es la prestación por desempleo al contabilizarse sólo los días trabajados a pesar de ser más amplio el periodo de cotización. A mayor abundamiento esta norma afecta a una proporción mayor de mujeres que de hombres, lo que introduce una importante diferencia de trato.

El Tribunal de Justicia concluirá que la citada cláusula $4.1^{\circ}$ del Acuerdo Marco no es aplicable a una prestación contributiva por desempleo como la controvertida y, por lo que respecta al art. $4.1^{\circ}$ de la Directiva 79/7/CEE, que éste se opone a una normativa nacional que, en el caso del trabajo a tiempo parcial vertical, excluye los días no trabajados del cálculo de los días cotizados, reduciendo de este modo el período de pago de la prestación por desempleo, cuando está acreditado que la mayoría de los trabajadores a tiempo parcial vertical son mujeres.

\section{EXTINCION DE CONTRATO POR FALTAS DE ASISTENCIA: PERSONAS CON DISCAPACIDAD}

Otra cuestión prejudicial, planteada por el Juzgado de lo Social $\mathrm{n}^{\circ} 1$ de Cuenca, preguntaba sobre la adecuación de art.52.d) del E.T a la Directiva 2000/78/CE del Consejo de 27 de noviembre, relativa al establecimiento de un marco general para la igualdad de trato en el empleo y la ocupación. La norma nacional contempla la extinción del contrato de trabajo por faltas de asistencia, aún justificadas, pero intermitentes, que alcancen el $20 \%$ de las jornadas hábiles en dos meses consecutivos, siempre que el total de faltas de asistencia en los doce meses anteriores alcance el 5\% de las jornadas hábiles o el $25 \%$ en cuatro meses discontinuos dentro de un período de doce meses, incluso cuando sean consecuencia de enfermedades atribuibles a la discapacidad de dicho trabajador. En consecuencia, el órgano comunitario se plantea si su aplicación a las personas con discapacidad puede encubrir una discriminación indirecta y suponer una vulneración de la Directiva europea en materia de igualdad y empleo. El asunto C-270/16 Carlos Enrique Ruiz Conejero contra Ferroser Servicios Auxiliares, S.A. y Ministerio Fiscal trae causa de la demanda presentada por un trabajador con un grado de discapacidad del $37 \%$ por razón de su obesidad que le provoca una limitación funcional de la columna. El demandante, en situación de Incapacidad Temporal durante una serie de períodos por problemas de salud con origen en su discapacidad, fue despedido por la acumulación de ausencias que excedieron el límite legal. En la demanda el trabajador alega la existencia de una vinculación directa entre las ausencias y su condición de discapacitado, por lo que el despido ha de ser considerado nulo por discriminatorio.

Para el Tribunal de Justicia la Directiva 2000/78/CE configura la discapacidad como una limitación de la capacidad derivada de dolencias físicas, mentales o psíquicas a largo plazo que, al interactuar con diversas barreras, pueden impedir la participación plena y efectiva de la persona de que se trate en la vida profesional en igualdad de condiciones con los demás trabajadores ${ }^{32}$.Por consiguiente, si la obesi-

32 STJUE de 9 de marzo del 2017, asunto C-406/15, Milkova. 
dad limita su capacidad, condicionando su participación plena y efectiva en la vida profesional en igualdad de condiciones con los demás trabajadores a causa de su movilidad reducida o a causa de la concurrencia de patologías que no le permitan realizar su trabajo o que le generen dificultades en el ejercicio de su actividad profesional, puede incluirse en el concepto de discapacidad establecido en la citada Directiva.

En la Sentencia de 18 de enero de 2018 el T.J.U.E declara que el hecho de tener reconocida la condición de persona con discapacidad en el sistema español no supone que automáticamente lo sea a efectos de la Directiva que se pretende aplicar, correspondiéndole al órgano judicial nacional comprobar su la incapacidad que padece se corresponde con el concepto establecido en la norma comunitaria.

El Tribunal de Justicia considera que el art. 52d) E.T no supone una discriminación directa, pues, se aplica a todas las personas de la misma manera si se da la situación de absentismo, reconociéndose, no obstante, que si podría declararse contrario a la Directiva si recogiese una discriminación indirecta contra las personas discapacitadas que sufren un riesgo adicional de estar de baja y se exponen a una posibilidad mayor de acumulación de bajas laborales. Estima que corresponde a las autoridades nacionales evaluar si podría estar justificada, tal como sostiene el Gobierno español, en combatir el absentismo y no va más allá de lo necesario para alcanzarla. En este sentido, se ha explicado como medida necesaria para reducir los costes laborales que asume el empresariado, costes directos como prestaciones de Seguridad Social por incapacidad temporal durante los primeros quince días de inactividad sin poder reclamar su devolución a la Tesorería General de la Seguridad Social, además de los costes de la sustitución; y el coste indirecto que supone la singular dificultad de suplir ausencias cortas. Sin embargo, también hay que tener en cuenta las normas nacionales de protección específica de las personas con discapacidad, como el artículo 40 del Real Decreto Legislativo 1/2013, de 29 de noviembre, por el que se aprueba el Texto Refundido de la Ley General de derechos de las personas con discapacidad y su inclusión social, que buscan prevenir o compensar las desventajas derivadas de la discapacidad, incluida la posible aparición de enfermedades vinculadas a ésta.

\section{EL T.J.U.E RECTIFICA Y CONFIRMA LA ADECUACIÓN DE LA LEGISLACIÓN NACIONAL AL DERECHO COMUNITARIO}

Desde que se conoció la sentencia De Diego Porras resultó obligado realizar determinadas precisiones para fijar el alcance de aquella jurisprudencia y llamar la atención sobre algunas incorrecciones o confusiones que se produjeron al tratar este asunto. Algo que se ha constatado con el reciente cambio de criterio del Tribunal de Justicia en sentencias de principios de este año en curso. Lo primero a reseñar es que, a pesar de las críticas que puedan merecer las normas españolas, nuestra realidad jurídica no es muy diferente a la de nuestro entorno, ya que es común que los estados europeos establezcan distintas modalidades de contratación con su respectivo régimen jurídico que comprende, obviamente, las indemnizaciones. Por otra parte, no puede desconocerse que los contratos de interinidad (objeto sobre el que se pro- 
nuncia el T.J.U.E), tan extendidos en la Administración Pública, existen en nuestro país desde 1980 no siendo una creación reciente. De hecho, su legalidad no es objeto de discusión.

En su primera sentencia de 2016, asunto Ana De Diego Porras vs Ministerio de Defensa, declaró que la extinción del contrato de interinidad (celebrado lícitamente) le daba derecho a la recurrente a cobrar la misma indemnización que le hubiese correspondido a la trabajadora sustituida funcionaria de plantilla (20 días de salario por año trabajado), ya que realizaban labores semejantes. A partir de las sentencias dictadas en 2016 se abrió un duro debate sobre la contratación temporal en España, al declararse que la legalidad española es contraria a la comunitaria. La resolución puso en tela de juicio el sistema de interinidad que se aplica, no sin abusos, por las Administraciones Públicas para cubrir un notable número de puestos de trabajo. En ellas el Tribunal de Justicia reconoce que tras la extinción de la relación laboral el personal funcionario temporal tiene los mismos derechos indemnizatorios que los trabajadores fijos y, además, les reconoce su condición de personal indefinido fijo si el contrato resultaba abusivo. En estas sentencias se pone el acento en la insuficiencia de garantías en el empleo público ante el encadenamiento de contratos temporales y se habilita a los órganos judiciales para que tomen las medidas más adecuadas y oportunas para asegurar que un puesto de trabajo fijo se cubra con un contrato de la misma naturaleza. Así se pondrá coto a la incertidumbre, la inestabilidad laboral y, en definitiva, al abuso que sufren, en su vida laboral, quienes trabajan con una concatenación de contratos temporales para cubrir un puesto fijo.

En la sentencia que dictó el Tribunal Superior de Justicia de Madrid, el 5 de octubre de 2016, hizo suya la argumentación del órgano comunitario declarando el derecho de la demandante a percibir la misma compensación que un trabajador fijo en un despido objetivo: 20 días por año trabajado ${ }^{33}$. En aplicación de este criterio comunitario, la Sala de lo Social del Tribunal Superior de Justicia del País Vasco dictó sentencia el 18 de octubre de 2016, reconociendo el derecho de una investigadora, que había sido contratada para "realizar un proyecto de investigación", a cobrar una indemnización de 20 días y no de 8 por la finalización de su contrato. La Sala estima que un contrato de investigación equivale a un contrato para obra o servicio deter-

33 https://www.google.es/url? $s a=t \& r c t=j \& q=\&$ esrc $=s \&$ source $=w e b \& c d=1 \& c a d=r j a \& u a$ $c t=8 \&$ ved $=0$ ahUKEwiiloiq $58 X P A h X H 1 R Q K H V x L B P 4 Q q Q I I J j A A \& u r l=h t t p \% 3 A \% 2 F \% 2 F e c o n$ omia.elpais.com\%2Feconomia\%2F2016\%2F10\%2F05\%2Factualidad\%2F1475669762_734249. html\&usg=AFQjCNGO-DT4ANPQgz8dZSrVi9FnYnSnUw (consultado el 6 de octubre de 2016). "Nuestra ley al autonomizar ciertas causas objetivas como instrumentos de la contratación temporal aboca al pernicioso efecto de que trabajadores con idéntica antigüedad y que realizan similar trabajo son tratados de manera divergente cuando el contrato se extingue. La cuestión no estriba en la consideración de que las causas del artículo 52 precitado sean aplicables al contrato de interinidad -que lo son- sino que la causa extintiva que se ha aplicado, conforme a la ley española, a la actora, negándole así cualquier derecho indemnizatorio, no le sería de aplicación si su contratación no fuera temporal, en cuyo caso tendría siempre, al menos, un derecho indemnizatorio de 20 días de salario por año trabajado si en la empresa se produjera la situación de exceso de trabajadores en relación con los puestos de trabajo reales desde la perspectiva de la productividad mercantil" $\left(\mathrm{FJ} 3^{\circ}\right)$. 
minado de más de 3 años de duración, correspondiéndole 20 días de indemnización, como si se hubiera despedido a una trabajadora fija por causas objetivas.

Las sentencias dictadas siguiendo el criterio europeo se han ido sucediendo ${ }^{34}$. La Sala de lo Social del Tribunal Superior de Justicia de Cataluña, al resolver un recurso de súplica, anuló la sentencia del órgano inferior que denegaba el derecho del trabajador despedido a cobrar la indemnización que le correspondería en caso de ser indefinido. En aplicación de la doctrina europea declara que "teniendo en cuenta que cuando se extingue un contrato de trabajo de un trabajador indefinido por causas objetivas tiene derecho a una indemnización de 20 días por año de servicio, hasta un máximo de una anualidad, la misma indemnización se tendrá que reconocer a otro trabajador temporal que también ve extinguido su contrato de trabajo por causas objetivas". En otro orden de cosas, es destacable que esta sentencia afirma la eficacia horizontal de la jurisprudencia europea, aplicándola a un caso de contratación privada.

Su homónimo andaluz, en sentencia de 16 de noviembre de 2017, equiparó la indemnización de un trabajador temporal, tras la finalización de su contrato, en este caso sólo había trabajado durante tres meses en una empresa de limpieza, a la de un empleado fijo despedido por causas objetivas ${ }^{35}$. En su Fundamento Jurídico Quinto recoge la argumentación del Tribunal de Justicia declarando que la doctrina contenida en la sentencia De Diego Porras debe ser aplicada a todos los contratos temporales, en este caso un contrato temporal eventual por acumulación de tareas, no sólo a los contratos de interinidad. Se declara que la Cláusula 4 del Acuerdo Marco incluye en el concepto de condiciones de trabajo la indemnización que el empresario está obligado a abonar a un trabajador tras la finalización de su contrato de trabajo de duración determinada, de modo que la respuesta del T.J.U.E se refiere a todos los contratos temporales, de manera que la extinción del contrato temporal eventual válidamente celebrado queda fijada en el art. $49.1^{\circ} \mathrm{C}$ ) del E.T en 12 días de salario por año de servicio.

Además, la norma comunitaria ofrece una definición de "trabajador temporal" como aquél que ha concertado directamente su contrato de trabajo o su relación laboral con un empresario, estando determinada la finalización del contrato o de la relación de trabajo por condiciones objetivas como una fecha concreta, la realización de una obra o servicio determinado o la producción de un hecho o acontecimiento determinado. En este concepto se integra el contrato temporal eventual celebrado entre la Ciudad Autónoma de Melilla y la trabajadora para atender la "necesidad temporal de personal a consecuencia del aumento de administrados que demandan

${ }_{34}$ Sentencia N 2316/2016, Tribunal Superior de Justicia de Asturias, Sala de lo Social, Sec. 1, Rec 2142/20.

35 https://www.google.es/url?sa $=t \& r c t=j \& q=\& e s r c=s \& s o u r c e=w e b \& c d=2 \& c a d=r j a \& u$ $a c t=8 \& v e d=0$ ahUKEwiYk 7 PNnrDTAhXJ5xoKHd4GCy0QFggpMAE\&url $=h t t p \% 3 \mathrm{~A} \% 2 \mathrm{~F} \% 2 \mathrm{Fw}$ ww.poderjudicial.es $\% 2 F$ search_old $\% 2 F$ doAction\%3Faction\%3Dcontentpdf\%26databasematch $\% 3 D A N \% 26$ reference\%3D7894720\%26links\%3D\%25221411\%252F2016\%2522\%26optimize\% 3D20161221\%26publicinterface\%3Dtrue\&usg=AFQjCNF6PTR4uhIeCLkxTO9iHQgFWXN9zQ (consultado el 17 de abril de 2017). 
ayudas de servicios sociales". En el contrato se fija una fecha cierta de finalización de la relación de trabajo y, además, la extinción se produce por una causa análoga a las descritas en el artículo 52 del E.T (productivas y organizativas), independientes de la voluntad del trabajador y que de ser causa de la extinción de otras relaciones de trabajo de carácter fijo dan derecho a la prestación económica indemnizatoria. Por todo lo anterior, el Tribunal concluye que no hay justificación para que tras la extinción del contrato perciba como indemnización 12 días de salario por año de servicio a diferencia de las extinciones por causas objetivas de un trabajador fijo comparable que conllevan una indemnización de 20 días de salario.

Recapitulando diremos que las sentencias dictadas por la jurisdicción social y la contencioso-administrativa han sido bastantes numerosas y contradictorias desde 2016, generando una buena dosis de inseguridad jurídica y confusión. Buena muestra de lo indicado han sido las constantes cuestiones prejudiciales como las C-574/16, C-677/16, C-212/17 y C-619/17. En las conclusiones presentadas por la Abogada General del Tribunal de Justicia de la Unión Europea ya se matizaba la doctrina allí contenida que influirá en las sentencias de los tribunales españoles. Así se colige de la afirmación de que no constituye discriminación de los trabajadores con contrato de trabajo de duración determinada, el hecho de que, tras la extinción de este vínculo, por haberse producido el hecho o acontecimiento acordado, no les corresponda indemnización o les corresponda una inferior respecto a otros trabajadores con contratos de duración indefinida cuando éste se extingue por una decisión empresarial por causas objetivas. En definitiva, la Abogada General declara que un contrato interino y otro indefinido no son comparables en términos de indemnización, pues si bien numerosas prestaciones económicas y sociales les corresponden tanto a unos como a otros - gratificaciones por lealtad, ayudas al transporte o guarderías- al reconocer el trabajo prestado, la indemnización no es una gratificación sino una compensación por el hecho de perder el trabajo y ahí entra en juego un factor de previsibilidad.

Como se comprueba, con este razonamiento se anunciaba un cambio de criterio respecto al expresado en septiembre de 2016 en la sentencia De Diego Porras que se materializó en dos sentencias dictadas el 5 de junio de 2018 resolviendo dos cuestiones prejudiciales, asuntos C-574/16, Grupo Norte Facility y Ángel Manuel Moreira Gómez, cuestión prejudicial del T.S.J de Galicia, en relación a un contrato temporal de relevo; y C-677/16, Lucía Montero Mateos y Agencia Madrileña de Atención Social, cuestión prejudicial del Juzgado de lo Social n ${ }^{\circ} 33$ de Madrid, en relación a un contrato de interinidad. Las nuevas sentencias del T.J.U.E confirman, a nuestro parecer, que la institución europea actuó en 2016 sin conocer la normativa española de forma correcta, si bien es de justicia reconocer que la redacción de la cuestión prejudicial, que dio lugar a estas resoluciones, no se lo puso fácil. Ahora se justifica la diferencia de trato entre temporales y fijos, confirmando la libertad de los estados miembros de diferenciar los modelos de contrato en su legislación laboral en función de los intereses nacionales ${ }^{36}$.

36 Ya en febrero de 2017, el presidente del TSJUE, declaró que faltó entendimiento entre el juzgado que realizó la consulta y los miembros de la Corte de Justicia Europea en el caso De Diego Porras, lo que ya anunciaba esta rectificación. 
En sus nuevas resoluciones declara que la finalización de un contrato de interinidad por vacante y de un contrato temporal de relevo se produce "en un contexto sensiblemente diferente, desde los puntos de vista fáctico y jurídico, de aquel otro contrato de trabajo fijo que se extingue debido a la concurrencia de una de las causas previstas en el artículo 52 del Estatuto de los Trabajadores". Por otra parte, en los contratos temporales las partes "conocen, desde el momento de su celebración, la fecha o el acontecimiento que determinan su término. Este término limita la duración de la relación laboral, sin que las partes deban manifestar su voluntad a este respecto tras la conclusión de dicho contrato"; mientras que "la extinción de un contrato fijo por una de las causas recogidas en el artículo 52 del Estatuto de los Trabajadores, a iniciativa del empresario, resulta del advenimiento de circunstancias que no estaban previstas en el momento de su celebración y que ponen en tela de juicio el desarrollo normal de la relación laboral". En virtud de esta argumentación, el abono a dicho trabajador despedido de una indemnización equivalente a veinte días de salario por año de servicio trata precisamente de compensar el carácter imprevisto de la ruptura de la relación de trabajo por una causa de esta índole, y, por lo tanto, "la frustración de las expectativas legítimas que el trabajador podría albergar, cuando tiene lugar la ruptura, respecto a la estabilidad de dicha relación", según la redacción de la sentencia ${ }^{37}$.

Ahora bien, sigue siendo necesario adoptar medidas legislativas reformistas que pongan coto a la temporalidad laboral que caracteriza nuestro mercado laboral.De hecho, tras el terremoto que se originó tras las sentencias de 2016, el Gobierno nombró un grupo de expertos que redactó unas Conclusiones provisionales que fueron remitidas por el Ministerio de Empleo y Seguridad Social a la Mesa del Diálogo Social para la Agenda Integral por la calidad en el empleo para adecuar las indemnizaciones. Todos los trabajos legislativos se han parado tras la rectificación del Tribunal de Justicia ${ }^{38}$. Como a nadie se le oculta la regulación española viene siendo objeto de revisión por la Unión Europea desde hace unos años, estimando que se vulnera la legislación comunitaria en materia de condiciones de trabajo, por lo que no resultó muy sorprendente la doctrina de 2016, sobre todo si tenemos en cuenta que las tres sentencias recayeron sobre temas clave en la contratación española como la diferencia de trato entre funcionarios de carrera y funcionarios eventuales respecto al cobro de complementos salariales por antigüedad, entendiendo que la existencia de un vínculo de carácter indefinido no es una justificación objetiva y razonable para fundamentar la negación de estos complementos. No obstante, en ningún caso, como se ha indicado en páginas anteriores, se declara la ilegalidad de la contratación temporal, pues en determinados sectores es necesario recurrir a esta modalidad. El tribunal se

37 Sobre indemnizaciones de los contratos temporales se esperan más sentencias, pues están pendientes de resolución varias cuestiones prejudiciales, una sobre el caso De Diego Porras promovida por el Tribunal Supremo, preguntando si la extinción del contrato temporal de interinidad conlleva el derecho a la indemnización prevista para los demás contratos temporales.

38 La Ley 3/2017, de 27 de junio, de Presupuestos Generales del Estado, ha aprobado un proceso de estabilización del personal al servicio de la Administración, estableciendo una serie de actuaciones con el objetivo de reducir el empleo temporal hasta un máximo del 8 por ciento durante el trienio 2017-2019. 
centró en las indemnizaciones, pero el principal problema reside en la tasa de temporalidad y su uso abusivo y fraudulento.

Por todo ello, podemos aventurar que a estas sentencias le seguirán otras que pondrán el foco en distintas cuestiones de nuestra legislación laboral que necesitan reformarse y adecuarse a la realidad social. El Derecho Laboral es un elemento básico en el Estado Social y el Estado no puede retirarse en la regulación de las relaciones laborales y derechos fundamentales de las personas trabajadoras, ampliando el margen de maniobra de otros operadores que se mueven por intereses económicos privados.

\section{BIBLIOGRAFÍA}

ABA CATOIRA, A.: "La efectividad de los derechos de los trabajadores y del empresariado desde la implantación de las tecnologías en el ámbito laboral" en Anuario de la Facultad de Derecho da Universidade da Coruña, nº 18, 2014, pp.79-106.

ABA CATOIRA, A.: "Los derechos de la generación electrónica en el ámbito laboral" en Revista de Derecho, no 12, 2011, pp.257-281; “Art. 28: Derechos de acción colectiva. Sindicación y Huelga" en A. TUNES (coord.): Derechos Fundamentales: Aspectos básicos y actuales, Andavira, Santiago de Compostela, 2017, pp. 539-566.

BALAGUER CALLEJÓN, F.: "Una interpretación constitucional de la crisis económica", en Revista de derecho constitucional europeo, Año 10, $\mathrm{n}^{\circ}$ 19, enero-junio, 2013, pp. 449-454.

BALAGUER CALLEJÓN, F., AZPITARTE SÁNCHEZ M., GUILLÉN LÓPEZ E., y SÁNCHEZ BARRILAO, J. F.: El Impacto de la Crisis Económica en las Instituciones de la UE y los Estados Miembros, Thompson Reuters Aranzadi, 2015.

BAYLOS GRAU, A., y PÉREZ REY, J.: "Sobre el Libro Verde: modernizar el derecho laboral para afrontar los retos del siglo XXI", Cuadernos de la Fundación Sindical de Estudios, núm. 5, 2006.

CANOTILHO, M.: "Austeridad y derecho constitucional: el ejemplo portugués", Democrazia\&Sicurezza, n. ${ }^{\circ}$ 1, 2016, VI. 31-71.

CRUZ VILLALÓN, J.: "Últimas tendencias en la jurisprudencia del Tribunal de Justicia de la Unión Europea" en Temas Laborales, núm.130, 2015, pp.13-46.

MANGAS MARTIN, A., y LIÑAN NOGUERAS, D.: Instituciones y Derecho de la Unión Europea, $9^{a}$ ed., Tecnos, Madrid, 2016.

MENÉNDEZ SEBASTIÁN, P.: "Inaplicación horizontal de la doctrina de Diego Porras. Comentario a la sentencia de 16-11-2016, rec.1439/2016, del TSJ Andalucía-Málaga" en Revista de Información Laboral, nº12, 2016, pp.153-165.

MONEREO PEREZ, J. L.: "La racionalización jurídica de las relaciones laborales y la emergencia de nuevas fuentes reguladoras en el orden internacional" en Lex Social, vol. 8, núm.1, 2018, pp.1-44

PALOMEQUE LÓPEZ, M. C: "Derechos fundamentales generales y relación laboral: los derechos laborales inespecíficos" en R. Martín Jiménez y A. Sempere Navarro 
(coords.): El modelo social en la Constitución española de 1978, Ministerio de Trabajo e Inmigración, 2003, pp.229-248.

PALOMEQUE LÓPEZ, M.C.: “Tres sentencias que estremecieron al mundo", en Trabajo y Derecho, $\mathrm{n}^{\circ}$ 23, 2016.

PÉREZ INFANTE, J.: “Las reformas laborales en la crisis económica: su impacto económico" en Ekonomiaz, n ${ }^{\circ} 87,1^{\circ}$ semestre, 2015, pp. 1-36.

REQUEJO, P.: "El papel de la crisis económica en la argumentación del Tribunal Constitucional. Comentario a la STC 119/2014” en Teoría y Realidad Constitucional, UNED, no 36, 2015, pp.417-437.

RODRÍGUEZ CRESPO, M. J: “Límites al uso abusivo de la contratación temporal por parte de las Administraciones Públicas. Un análisis a la luz de los recientes pronunciamientos del T.J.U.E: asuntos maría Elena López contra el Servicio Madrileño de Salid y Martínez Andrés (C-16/15) y Otro contra el Servicio Vasco de Salud (C-184/15) en Revista de Información Laboral, nº 4, 2017, pp. 57-69.

RODRÍGUEZ IGLESIAS G., VALLE GÁLVEZ, G. y A: “El Derecho Comunitario y las relaciones entre el Tribunal de Justicia de las Comunidades Europeas, El Tribunal Europeo de Derechos Humanos y los Tribunales Constitucionales", 1997.

RODRÍGUEZ-PIÑERO Y BRAVO-FERRER, M., CASAS BAAMONDE, Ma E.: "La igualdad de trato en la contratación temporal, el derecho de los trabajadores interinos a indemnización por la finalización de su contrato por "causa objetiva", y los encadenamientos abusivos de contratos y relaciones de servicios temporales en las Administraciones Públicas españolas. Las sentencias del Tribunal de Justicia de la Unión Europea de 14 de septiembre de 2016" en Derecho de las Relaciones Laborales, $n^{\circ}$ 9, 2016.

TORRECILLA, E.: "El Tribunal de Justicia de la Unión Europea y el impacto de su reciente jurisprudencia en la regulación de la contratación temporal en España y el derecho a indemnización por extinción del contrato" en LanHarremanak. Revista de Relaciones Laborales, $n^{\circ} 36,2017$, pp.18-19. 